\title{
Effects of abrasive particles on liquid superlubricity and mechanisms
}

\section{for their removal}

Xiangli Wen, Pengpeng Bai, Yuanzhe Li, Hui Cao, Shaowei Li, Bin Wang, Jingbo

Fang, Yonggang Meng, Liran Ma* and Yu Tian*

State Key Laboratory of Tribology, Department of Mechanical Engineering, Tsinghua University, Beijing 100084, China;

*Corresponding author.Yu Tian (tianyu@mail.tsinghua.edu.cn); Liran Ma (maliran@mail.tsinghua.edu.cn) 


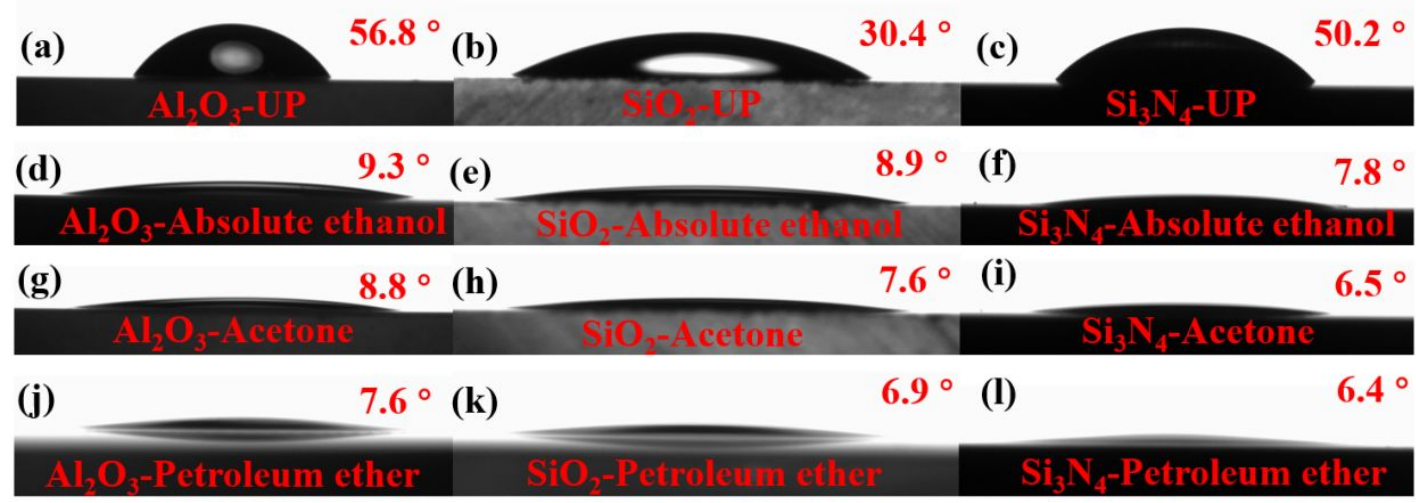

Figure S1. Contact angles of different solvents on friction-pair surfaces. 

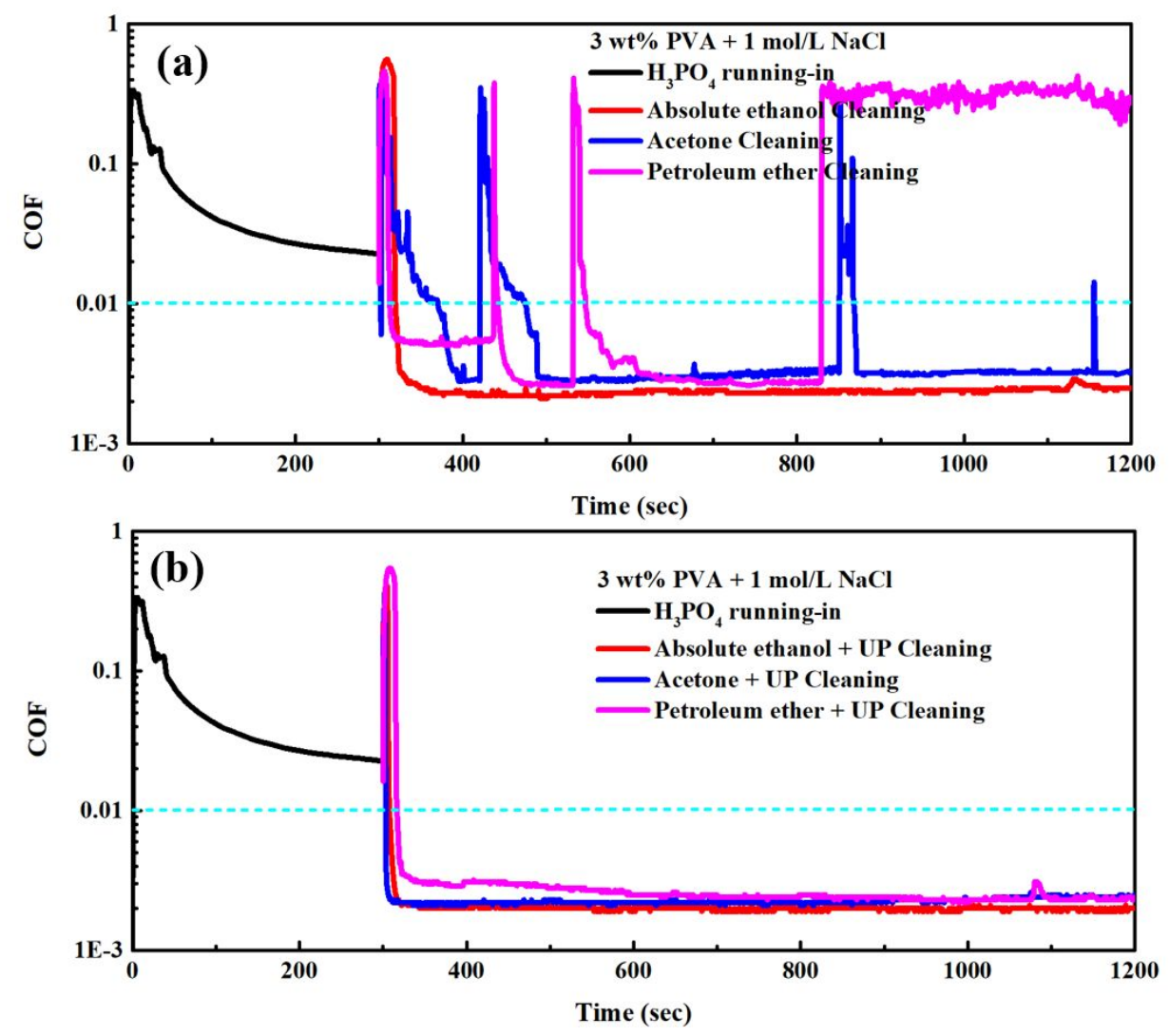

Figure S2. COF as a function of time under lubrication with $3 \mathrm{wt} . \% \mathrm{PVA}+1 \mathrm{~mol} / \mathrm{L}$

$\mathrm{NaCl}$. After running-in $\mathrm{H}_{3} \mathrm{PO}_{4}$, the friction-pair surfaces were cleaned with (a) organic solvents and (b) organic solvent + UP. 


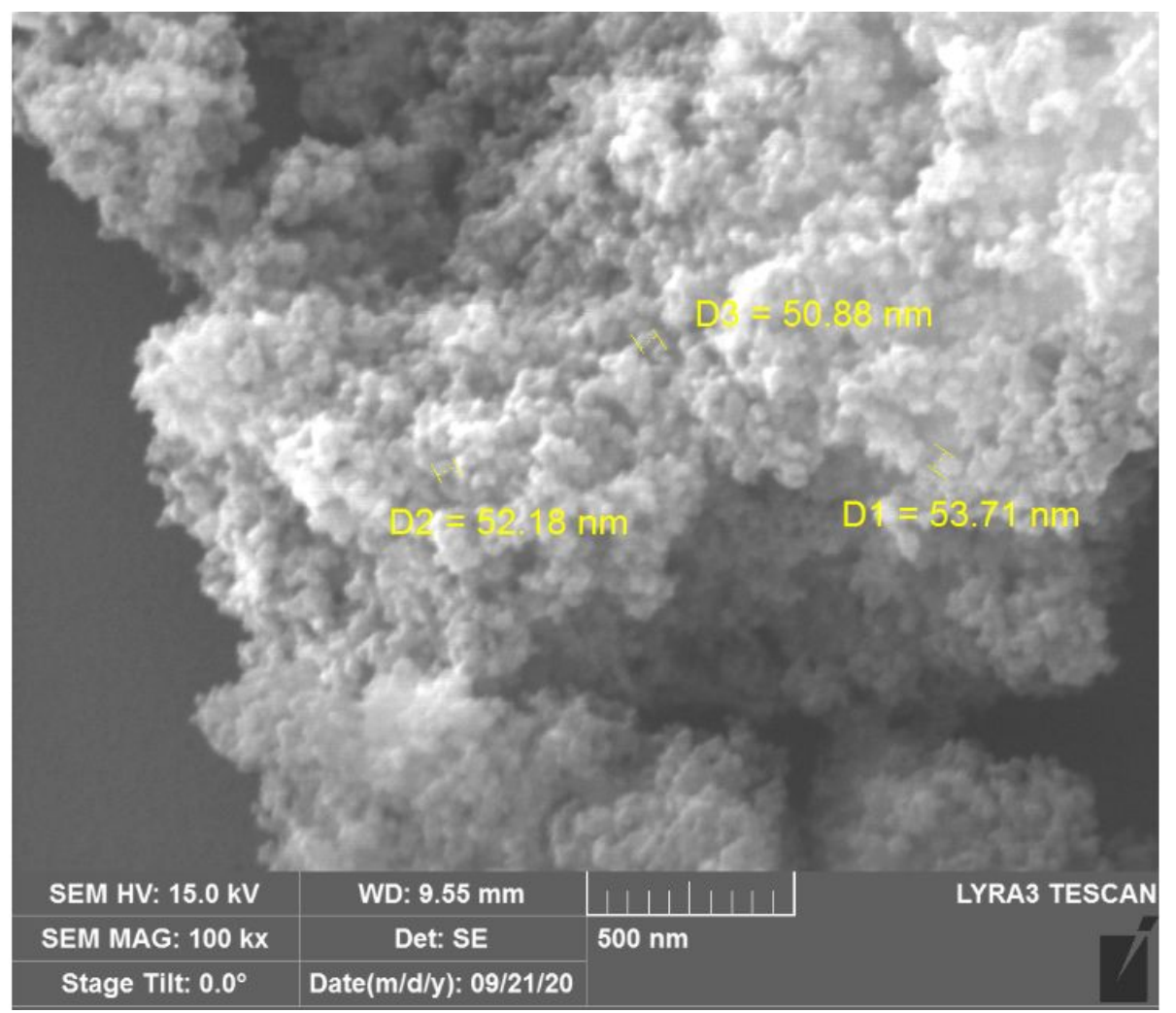

Figure S3. SEM image of $\mathrm{SiO}_{2}$ nanoparticles. 

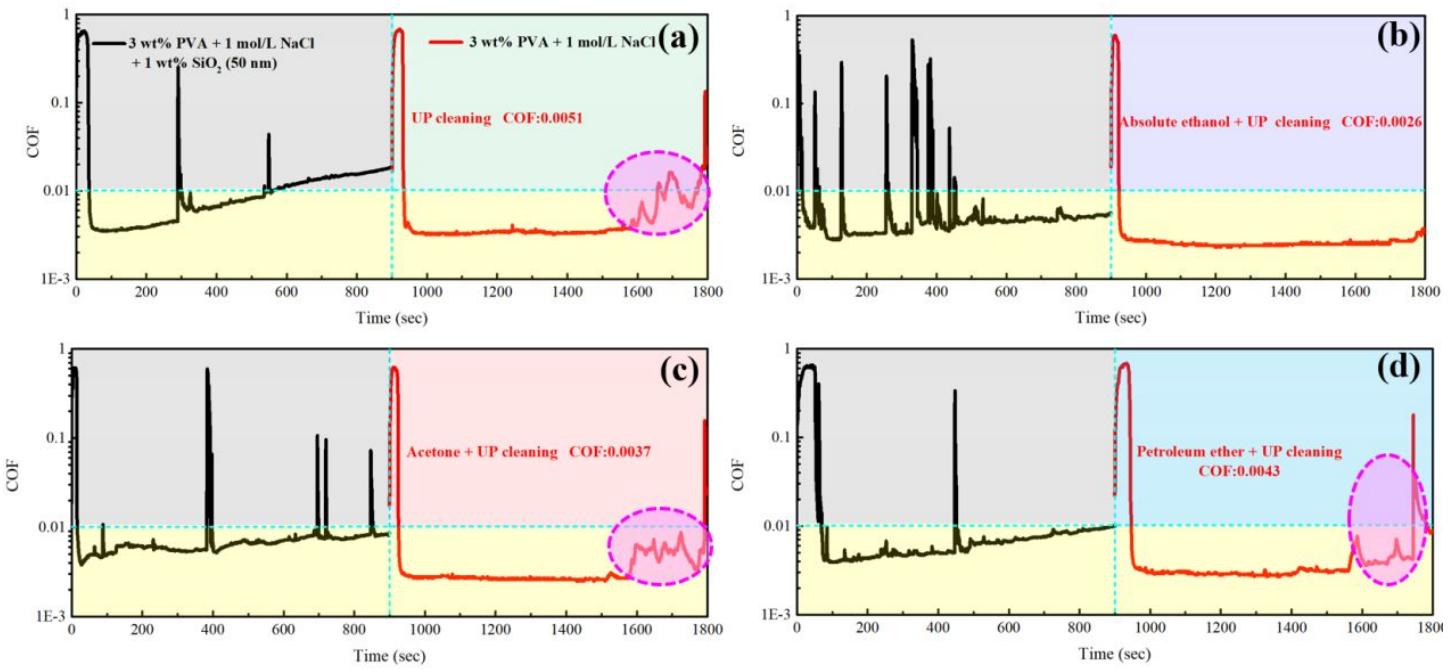

Figure S4. COF of 3 wt. $\%$ PVA $+1 \mathrm{~mol} / \mathrm{L} \mathrm{NaCl}$ during lubrication after running-in with 3 wt. $\% \mathrm{PVA}+1 \mathrm{~mol} / \mathrm{L} \mathrm{NaCl}+1$ wt. $\% \mathrm{SiO}_{2}$ and cleaning the friction pair with different solvents. 

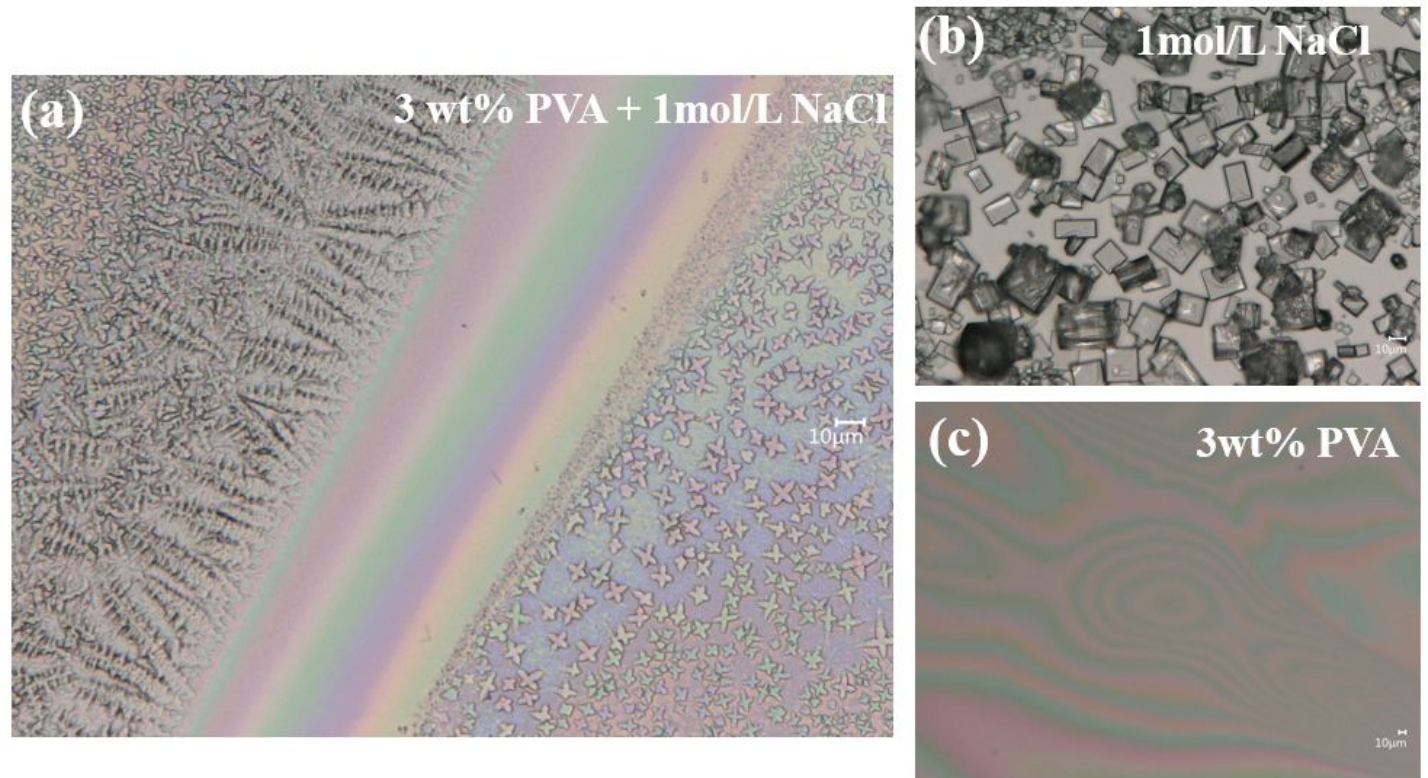

Figure S5. Crystallization of (a) 3 wt. $\% \mathrm{PVA}+1 \mathrm{~mol} / \mathrm{L} \mathrm{NaCl}$, (b) $1 \mathrm{~mol} / \mathrm{L} \mathrm{NaCl}$, and (c) 3 wt.\% PVA on the surface of sapphire disks, as observed by optical microscopy. 

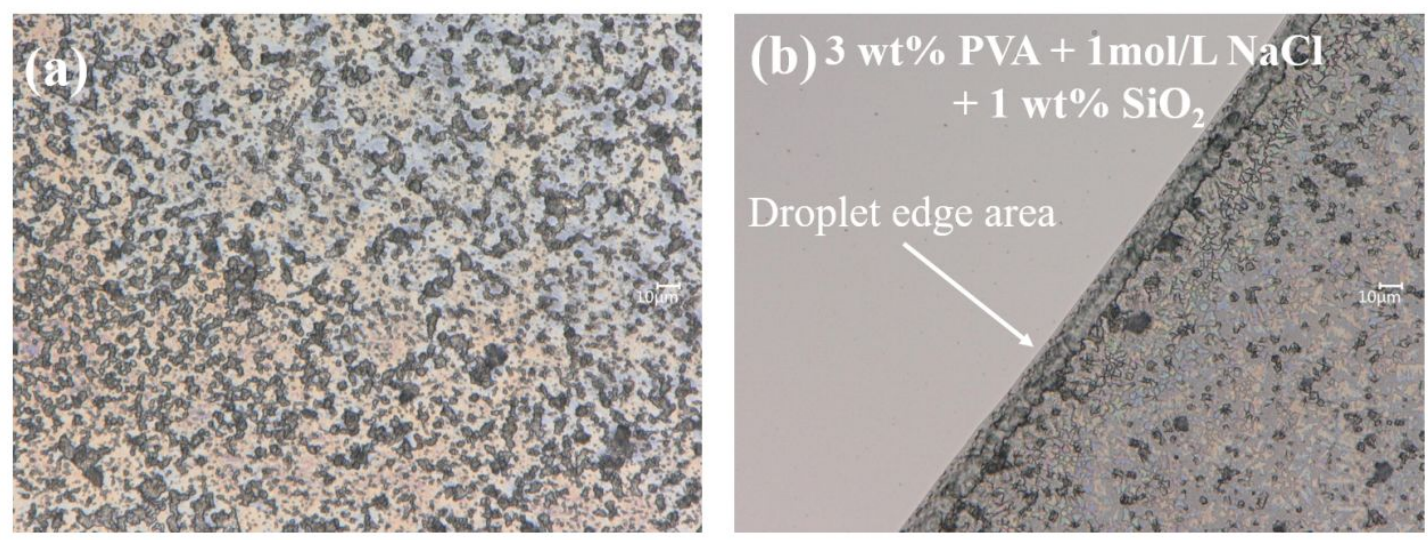

Figure S6. Crystallization of 3 wt. $\%$ PVA $+1 \mathrm{~mol} / \mathrm{L} \mathrm{NaCl}+1$ wt. $\% \mathrm{SiO}_{2}$ on the surface of a sapphire disk, as observed by optical microscopy. 

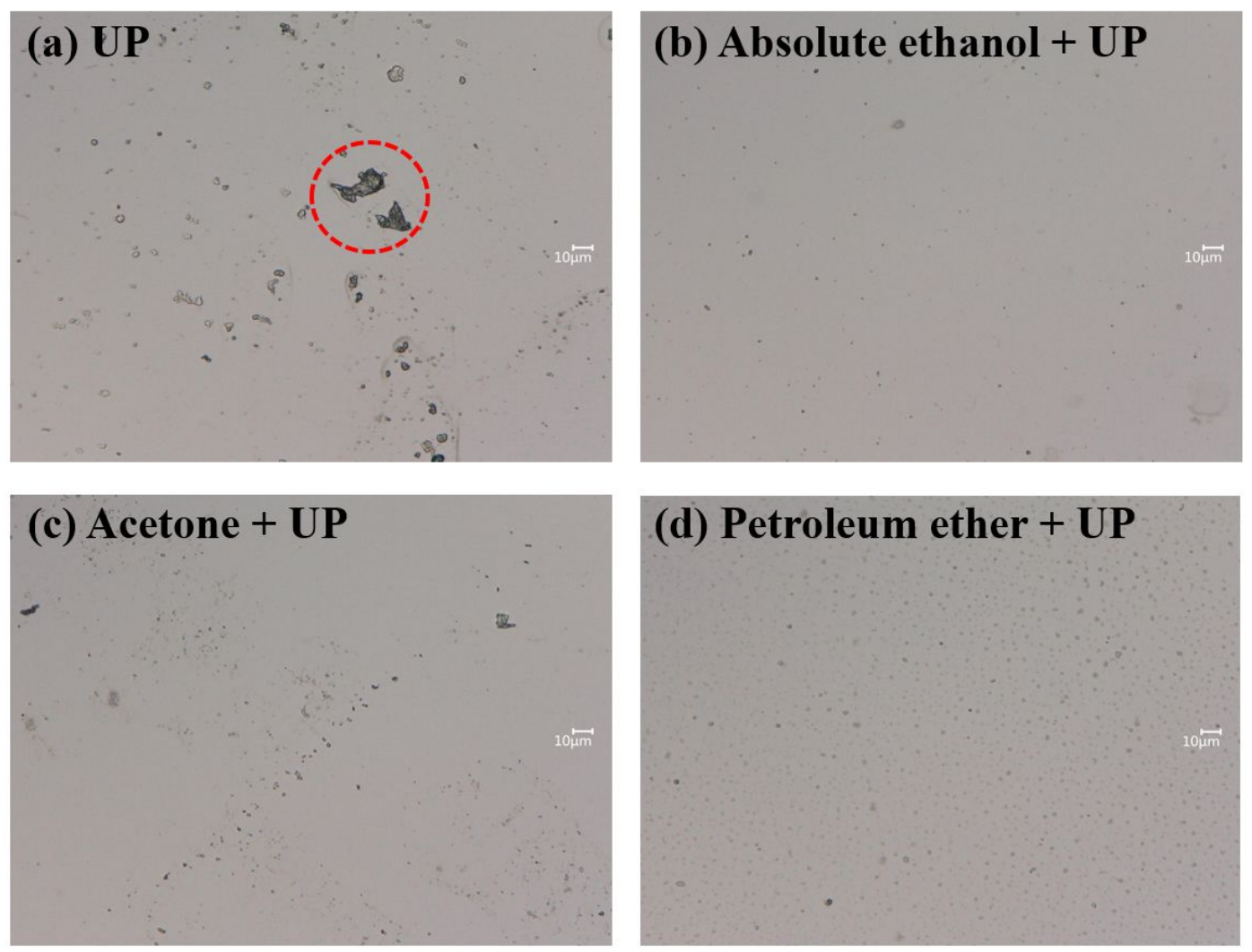

Figure S7. Optical microscopy images of cleaned sapphire surfaces soaked in (a) UP for $10 \mathrm{~min}$ and $(\mathrm{b}-\mathrm{d})$ organic solvents + UP for $5 \mathrm{~min}$. 

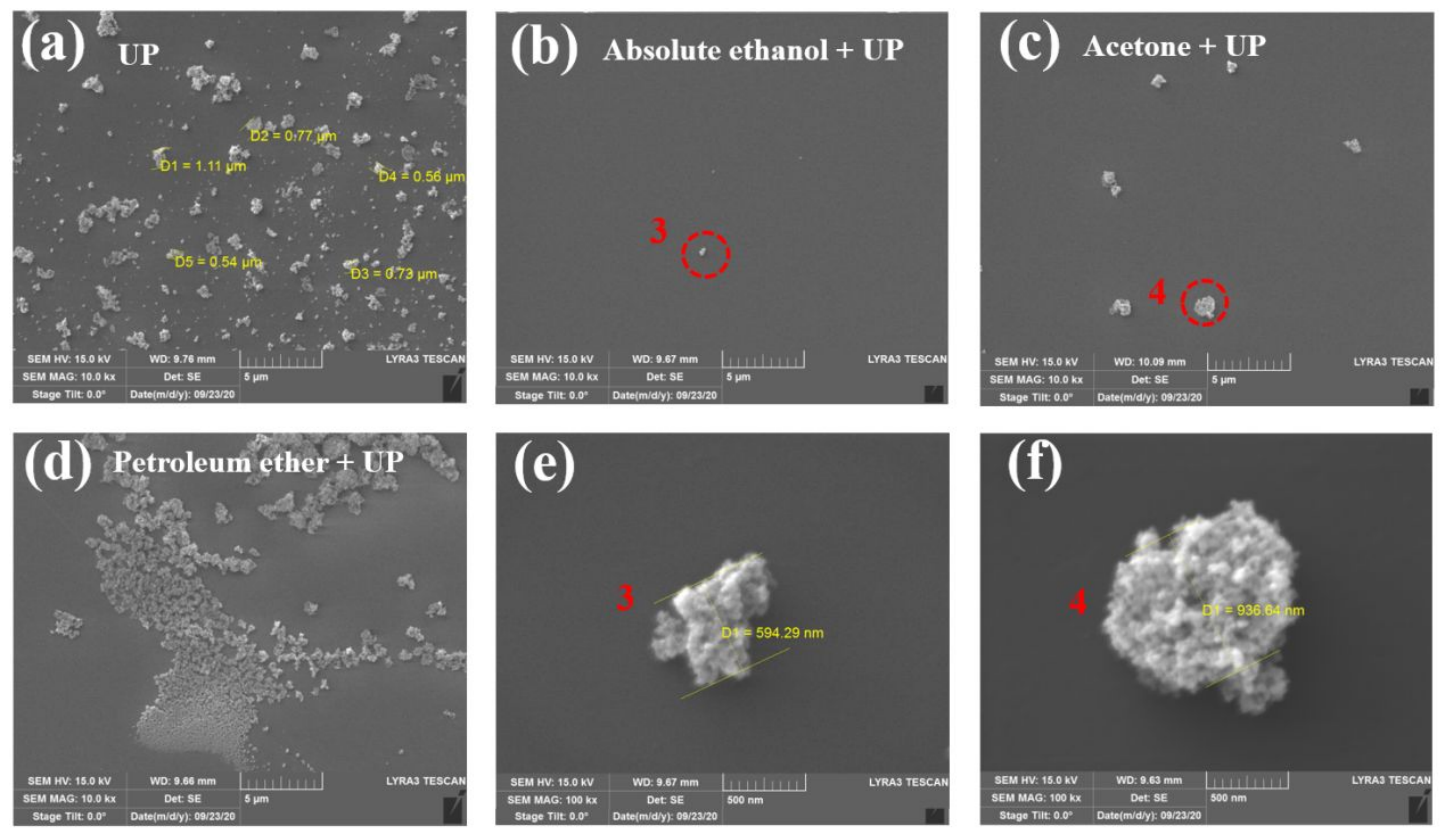

Figure S8. SEM images of $\mathrm{SiO}_{2}$ particles remaining on the surface of $\mathrm{SiO}_{2}$.

Ultrasonicated in (a) UP for $10 \mathrm{~min}$ and (b-d) organic solvents + UP for $5 \mathrm{~min}$. (e and f) Partially enlarged views of (b and c), respectively. 


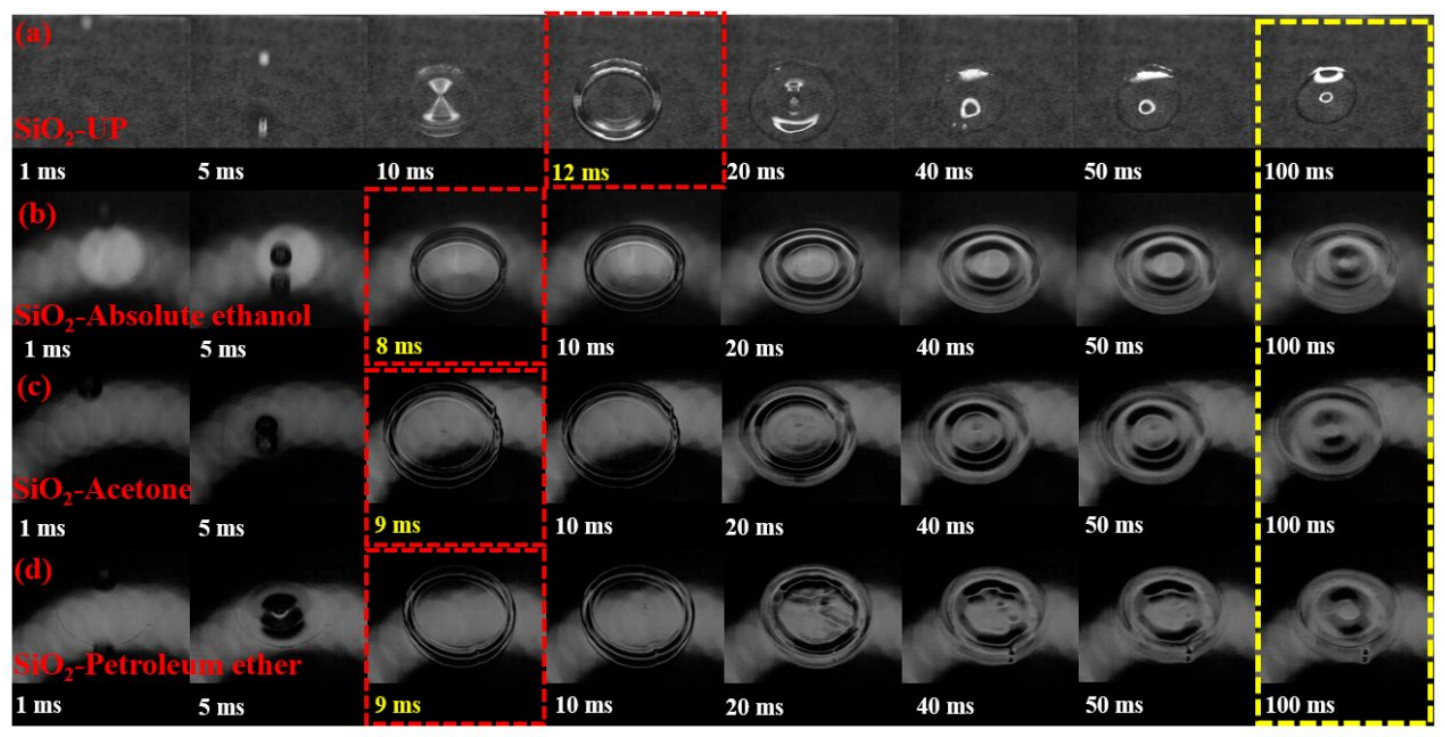

Figure S9. Spreading of droplets on the surface of $\mathrm{SiO}_{2}$ wafers. (a) UP, (b) absolute ethanol, (c) acetone, and (d) petroleum ether. 